\title{
FORCED INDUCTION DEVICES - BLOWING AWAY, EVERY MILLISECOND
}

The demand for personal transportation is dependent on vehicle demand, which in turn is dependent on the country's GDP. The US car and truck sales touched a record $17.4 \mathrm{mn}$ units, while car sales in India have been on a growth path for 14 consecutive months (13\% in December 2015). These trends and stricter emission norms are positives for forced induction devices.

In India, the growth of cars per 1,000 people has been eight in 2000, 18 in 2012 and 24 in 2015. The CO2 norms at $130 \mathrm{gm} / \mathrm{km}$ in 2016 will get to 113 $\mathrm{gm} / \mathrm{km}$ in 2021 and BS VI emission norms will come by April 2020. These changes and stricter noise and emission norms will change the paradigm for turbochargers, as the market will create a pull in their deployment.

The other ground reality also indicates more number of older vehicles in the global vehicle park. The growth in US passenger vehicles in 15 years has been $20 \mathrm{mn}$ vehicles, in China it has gone from 20 to $150 \mathrm{mn}$ and in India it is at 23.4 million in 2015. This population does not open opportunities for new generation retrofits except the few in replacement markets.

Superchargers were mainly used with bigger engines in sporty vehicles or for endurance races, until recently. They are now being deployed beyond the big engines of premium sports vehicles. They are being used for increasing fuel economy and reducing emissions. OEMs have integrated them in $\mathrm{C}$ segment vehicles to increase fuel economy by four to five per cent with smaller engines that are below 21 .

In the past, many manufacturers supplied standard devices developed for other vehicles and markets to OEMs that had to adapt their engines and control architectures for these devices. Today, it is an imperative for these device manufacturers to work with engine manufacturers and vehicle development teams to co-develop optimised solutions at an affordable cost. The type of device on a vehicle is now a part of the product development early decision process - whether electric, multi stage, carbon fibre-based or super plastic materials or other composites. Packaging these devices and integrating them under the hood is a technical art. The exhaust manifolds and outlets are designed for lowest pressure losses, least back pressure \& noise, and best thermal efficiency.

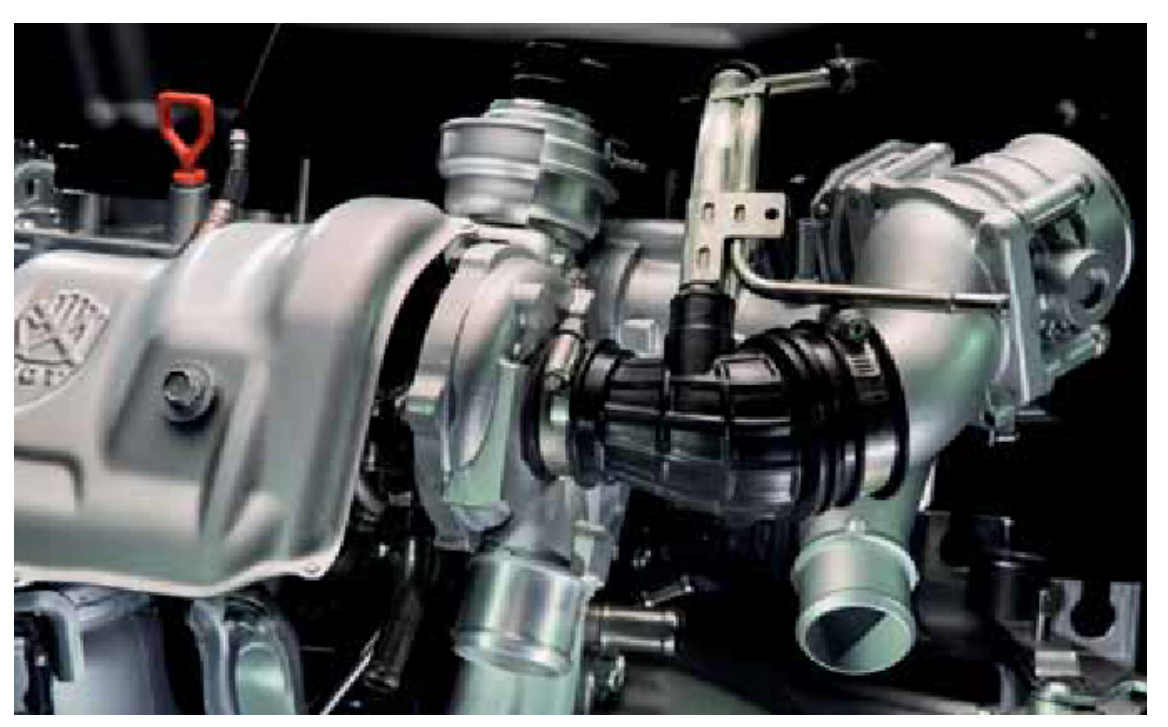

\section{NEWER CHALLENGES}

Manufacturers of forced induction devices have newer challenges in front of them - increasing urban mobility and XEV growth have resulted in lesser travel kilometres per person per year in spite of rapidly developing expressways in emerging economies. The growth of car sharing and collective car usage, fleets usage by mobility providers are not real opportunities. The changing ecosystem and total cost of ownership will drive investment decisions for development and growth of such devices. In the urban environment, compact cars and B-segments hardly provide opportunities.

As the ecosystem for smart vehicles and autonomous driving expands, the need for intelligence in these devices will become important. The ability to de-power or enhance power in the devices could become a competitive advantage for manufacturers of smart mobility. The innovations in virtual power management will help downsize engines and increase options for 'power on demand', thus reducing overall cost. In such scenarios, forced induction devices could become decision gateways and conduits of power transfer. These devices could play an important role in fleet management to monitor and regulate safe driving, to learn and emulate driving habits and drive cycles.

These devices will grow further to be an integral part of engines and vehicle power management strategy with a lot more intelligence for safer, smarter and sustainable mobility. 